\title{
Neutrophil Lymphocyte Ratio (NLR) is an Indicator of Coronary Artery Disease (Cad) in Type 2 Diabetes Mellitus Patients
}

\author{
Bhuiyan MMA1*, Sultana $\mathrm{S}^{2}$, Hasan $\mathrm{A}^{3}$, Barua $\mathrm{D}^{4}$, Ahmed $\mathbf{M}^{1}$, \\ Sultana $\mathrm{T}^{5}$ and Choudhury $\mathrm{AA}^{6}$ \\ ${ }^{1}$ Department of Laboratory Medicine, Dhaka Medical College Hospital, Bangladesh \\ ${ }^{2}$ Department of Obstetrics \& Gynaecology, Anwer Khan Modern Medical College \\ Hospital, Bangladesh
}

${ }^{3}$ Director General of Health Services, Mohakhali, Bangladesh

Research Article

Volume 2 Issue 1

Received Date: October 22, 2018

Published Date: November 01, 2018

DOI: $10.23880 /$ cprj-16000112

${ }^{4}$ Department of Medicine, Chittagong Medical College Hospital, Bangladesh

${ }^{5}$ Department of Laboratory Medicine, Bangabandhu Sheikh Mujib Medical University, Bangladesh

${ }^{6}$ Department of Otolaryngology- Head \& Neck Surgery, Bangabandhu Sheikh Mujib Medical University, Bangladesh

*Corresponding author: Mohammad Monzurul Alam Bhuiyan, Clinical Pathologist, Department of Laboratory Medicine, Dhaka Medical College Hospital, Bangladesh, Email: drmonzucmc@gmail.com

\section{Abstract}

Background: Coronary artery disease (CAD) is the leading cause of death in type 2 diabetes mellitus (DM) patients. DM is a significant risk factor in atherosclerotic cardiovascular disease (CVD). We aimed to investigate relationship between Neutrophil lymphocyte ratio (NLR) and CAD proven with angiography in type 2 DM and to establish NLR as a useful indicator of CAD in type 2 DM patient.

Objective: To assess the NLR as a predictive marker for CAD in patients with type 2 diabetes mellitus.

Methods: This case control study was conducted in the Department of Clinical Pathology in collaboration with Department of Cardiology, Bangabandhu Sheikh Mujib Medical University (BSMMU), Shahbag, and Dhaka from March 2014 to February 2015. Total 134 patients were enrolled in this study who were waiting for further percutaneous coronary intervention (PCI) in the Department of Cardiology, BSMMU; 84 cases were considered as Group I (DM with CAD) and 50 controls were Group II (DM without CAD). A $2 \mathrm{ml}$ of blood was collected in EDTA tube from the patients prior to PCI for complete blood count (CBC) were measured by hematology auto analyzer, rechecked manually and NLR was calculated in the Department of Clinical Pathology, BSMMU. Coronary artery disease with 50\% coronary artery stenosis and more critical lesion that were diagnosed by PCI were included in this study as cases. Coronary artery disease with less than $50 \%$ coronary artery stenosis that was diagnosed by PCI was included in this study as control. The statistical analysis was done by Chi-square test and unpaired sample ' $t$ ' test.

Results: NLR was higher in CAD (+) group compared to group without CAD (-) $(2.76( \pm 0.74)$ vs $1.56( \pm 0.15)$, p<0.001). 
Conclusion: NLR was higher in DM patients with angiographically proven CAD compared to those DM patients without CAD. NLR may be a useful marker to predict the presence of CAD in type 2 DM patients.

Keywords: Neutrophil lymphocyte ratio; Diabetes mellitus; Coronary artery disease

Abbreviations: CAD: Coronary Artery Disease; CVD: Cardiovascular Disease; NLR: Neutrophil Lymphocyte Ratio; PCI: Percutaneous Coronary Intervention; CBC: Complete Blood Count; BSMMU: Bangabandhu Sheikh Mujib Medical University; CHD: Chronic Heart Disease; WBC: White Blood Cell; ESR: Erythrocyte Sedimentation Rate; FPG: Plasma Glucose- Fasting; PPBG: Plasma Glucose 2 Hours After 75 G Glucose; HBA1c: Glycated Hemoglobin; ALT: Alanine Amino Transferase.

\section{Introduction}

Diabetes is a group of metabolic disorders characterized by hyperglycemia resulting from defects in insulin secretion, insulin action, or both [1]. According to WHO report, Bangladesh had 3.2 million of diabetic subjects in 2000 and the number is expected to increase to a staggering 11.1 million by 2030 [2]. Type 2 DM is a chronic disease associated with many complications. There is two to four fold increased risk of cardiovascular disease in type 2 DM patients. (Tables 1 \& 2) About $52 \%$ cause of death in type 2 DM is cardiovascular disease [3]. Several mechanisms are likely to contribute to the accelerated atherosclerosis and increased chronic heart disease (CHD) risk in patients with type 2 diabetes mellitus. Important factors of premature coronary atherosclerosis include dyslipidemia, hypertension, hypercoagulability, poor glycemic control, smoking, obesity and lack of physical activity [4]. Most important factors are hyperglycemia affecting the vessel wall, diabetic dyslipidemia, hyperglycemia against dyslipidemia and chronic inflammation in the vessel wall [5].

\begin{tabular}{|l|c|c|c|}
\hline & $\begin{array}{c}\text { Group-I } \\
\text { Mean } \pm \text { SD } \\
(\mathbf{n = 8 4 )}\end{array}$ & $\begin{array}{c}\text { Group-II } \\
\text { Mean } \pm \text { SD } \\
(\mathbf{n = 5 0 )}\end{array}$ & P value* \\
\hline HbA1c (\%) & $7.40 \pm(1.04)$ & $6.13 \pm(0.65)$ & $<0.001$ \\
\hline
\end{tabular}

Table 1: Mean difference between Group-I (DM with CAD) and Group-II (DM without CAD) with HbA1c (\%) $(n=134)$.

* Unpaired sample t test was done to measure level of significance.

\begin{tabular}{|c|c|c|c|}
\hline Lipid profile & $\begin{array}{l}\text { Group I } \\
(n=84)\end{array}$ & $\begin{array}{c}\text { Group II } \\
(n=50)\end{array}$ & $P$ value $*$ \\
\hline $\mathrm{g} / \mathrm{dl})$ & $187.75( \pm 39.16)$ & $150.0( \pm 17.87)$ & \multirow{2}{*}{$<0.001$} \\
\hline Range & $115-320$ & $96-183$ & \\
\hline HDL (mg/dl) & $30.61( \pm 6.12)$ & $44.22( \pm 11.55)$ & \multirow{2}{*}{$<0.001$} \\
\hline Range & $22-60$ & $28-90$ & \\
\hline LDL (mg/dl) & $108.77( \pm 17.83)$ & $83.20( \pm 10.02)$ & \multirow{2}{*}{$<0.001$} \\
\hline Range & $68-170$ & $51-108$ & \\
\hline TG (mg/dl) & $179.35( \pm 19.60)$ & $142.02( \pm 17.65)$ & \multirow{2}{*}{$<0.001$} \\
\hline Range & $118-230$ & $118-230$ & \\
\hline
\end{tabular}

Table 2: Mean difference between Group-I and Group-II with lipid profile $(\mathrm{n}=134)$.

* Unpaired sample t test was done to measure level of significance

$\mathrm{TC}=<0.001$

$\mathrm{HDL}=<0.001$

$\mathrm{LDL}=<0.001$

$\mathrm{TG}=<0.001$.

The relationship between various inflammatory markers and CAD has been established [6]. Among these markers, the levels of white blood cell (WBC) subtypes confirmed inflammatory markers that play a crucial role in the pathogenesis of atherogenesis and atherothrombosis [7], have received significant attention. It has been established that the WBC count and levels of WBC subtypes not only play an important role in the development of CAD, but can also be used to predict the clinical outcomes of patients with CAD [8].

Neutrophil lymphocyte ratio (NLR) is the sign of balance between Neutrophil lymphocyte levels in the body and an indicator of systemic inflammation [9]. NLR is a new indicator for cardiovascular risk and mortality and by which we can predict the risk of coronary artery disease in type 2 DM patients [10]. Increased NLR is associated with major adverse cardiac events in diabetic patients $[11,12]$. 
In this study, we aimed to investigate relationship between NLR and CAD proven with angiography in type 2 DM and to establish NLR as a useful indicator of CAD in type 2 DM patient (Table 3 ).

\begin{tabular}{|c|c|c|c|}
\hline & \multicolumn{2}{|c|}{ Sex } & \multirow{2}{*}{$\begin{array}{c}P \text { - } \\
\text { value* }\end{array}$} \\
\hline & Male Mean \pm SD & Female Mean \pm SD & \\
\hline NLR & $2.44( \pm 0.82)$ & $1.92( \pm 0.76)$ & \multirow[b]{2}{*}{0.008} \\
\hline $\begin{array}{c}\text { Range } \\
\text { (min-max) }\end{array}$ & $1.23-7.0$ & $1.25-5.0$ & \\
\hline
\end{tabular}

Table 3: Distribution of mean NLR with sex $(n=134)$. * Unpaired sample $t$ test was done to measure level of significance.

\section{Methods}

This case control study was conducted at the Department of Clinical Pathology in collaboration with the Department of Cardiology, Bangabandhu Sheikh Mujib Medical University (BSMMU), Shahbag, Dhaka from March 2014 to February 2015. 134 type 2 DM patients were enrolled in this study; 84 cases were considered as Group I (DM with CAD) and 50 controls were Group II (DM without CAD).

Type 2 DM patients with coronary artery disease who have $\geq 50 \%$ stenosis, adults (18 years and above) patients, patients of both sexes were included in this study. Recurrent myocardial infarction, patients with congenital cardiac disease as shunt or vascular anomalies, pulmonary hypertension (both primary or secondary), acute or chronic infectious diseases, uncontrolled hypertension, known case of patients with cerebrovascular diseases, patients with documented malignancy, hematological disorders, patients with hepatic and renal impairment were excluded from the study. In this study patient's complete blood counts were measured by hematology auto analyzer (SYSMEX 4000i), rechecked manually and NLR was calculated in the Department of Clinical Pathology, BSMMU.

After selection, all the patients were thoroughly informed about the aims, objectives and procedure of the study and were encouraged for their voluntary participation (Tables $4 \& 5$ ). Then an informed written consent was taken from each subject. A detail personal, medical, occupational, educational and smoking history was recorded in a preformed data schedule and thorough physical examinations were done and documented. Tests done in Dept. of Clinical Pathology: CBC with PBF including differential count of WBC, erythrocyte sedimentation rate (ESR) and Neutrophil lymphocyte ratio (NLR). Reports collected from patient's file were: plasma glucose- fasting (FPG), plasma glucose 2 hours after 75 g glucose (PPBG), glycated hemoglobin (HbA1c), serum lipid profile, serum creatinine, alanine amino transferase (ALT).

\begin{tabular}{|c|c|c|c|}
\hline & $\begin{array}{c}\text { Group-I Mean } \\
\mathbf{\pm S D}\end{array}$ & $\begin{array}{c}\text { Group-II Mean } \\
\mathbf{\pm S D}\end{array}$ & $\begin{array}{c}\boldsymbol{P} \\
\text { value }^{*}\end{array}$ \\
\cline { 1 - 3 } NLR (Ratio) & $2.76( \pm 0.74)$ & $1.56( \pm 0.15)$ & \multirow{2}{*}{00.001} \\
\cline { 1 - 3 } $\begin{array}{c}\text { Range (min- } \\
\text { max) }\end{array}$ & $2.0-7.0$ & $1.23-1.74$ & \\
\hline
\end{tabular}

Table 4: Mean NLR difference between Group-I and Group-II (n=134).

* Unpaired sample t test was done to measure level of significance.

Cut off value of NLR was 1.74 .

\begin{tabular}{|c|c|c|c|c|}
\hline & $\begin{array}{c}\text { Cut of } \\
\text { value }\end{array}$ & Sensitivity & Specificity & Accuracy \\
\hline $\begin{array}{c}\text { Neutrophil } \\
\text { lymphocyte } \\
\text { ratio (NLR) }\end{array}$ & 1.74 & $98 \%$ & $58 \%$ & $\mathrm{p}<0.001$ \\
\hline
\end{tabular}

Table 5: Neutrophil lymphocyte ratio and Group-I (DM with CAD) for evaluation of coronary artery disease (CAD).

\section{Results}

A total 134 type 2 DM patients were included in the study. 84 cases were considered as Group I (DM with CAD) and 50 controls were Group II (DM without CAD).

The mean age of the DM with CAD (Group I) was $54.73 \pm 8.94$ years, the mean age of the DM without CAD (Group II) was $53.10 \pm 9.47$ years (Figure 1).

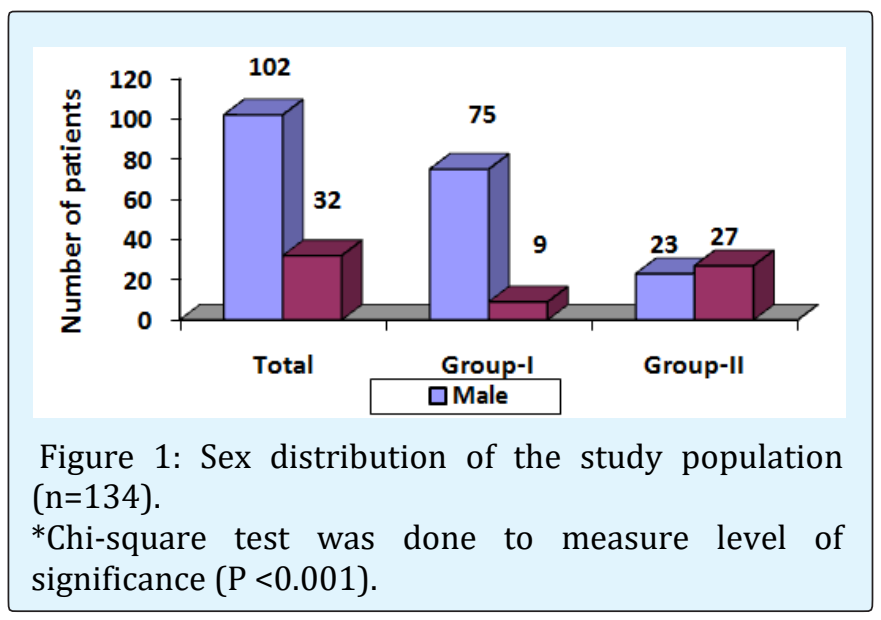




\section{Discussion}

Neutrophil lymphocyte ratio (NLR) is the sign of balance between neutrophil and lymphocyte levels in the body and an indicator of systemic inflammation [13]. NLR is a new predictor for cardiovascular risk and mortality. NLR could play an important role in early detection of atherosclerosis in diabetic patients and by which we can initiate early treatment [14].

Coronary artery disease occurs at any adult age, but it is the disease of middle and old age. In our study, the mean age of the patients in Group I (DM with CAD) was $54.73( \pm 8.94)$ years as compared to $56.59 \pm 13.63$ years and $58.01 \pm 12.9$ years, studies done by Assiri AS, et al. and Al-Saif SM, et al. $[15,16]$. It was $52.0 \pm 8.6$ years in a study reported by Siddique MA, et al. [17] and 56.6 years by Ullah M, et al. [18] in Bangladesh.

There was clear male predominance in Group I (89.28\%). In Group II there was $46 \%$ male. The difference was statistically significant between the groups (p $<0.001$ ). Our study is consistent with findings of study done by Bittencourt C, et al. [19]. They also found male predominance. They found that in patients with CAD group, male patient was $61.2 \%$ and in the other group male patient was $40 \%$. There was also statistically significant association between the groups ( $p<0.001)$. Our findings are also similar with the results found in the study conducted by Sonmez O, et al., Sayeed MA, et al., Paudel R, et al., Joshi P [20-22].

Glycemic control, measured here by HbA1c, was associated with CAD among type 2 DM patients. In our study, it was observed that mean $\mathrm{HbA1c} \%$ was significantly higher in the DM with CAD group $(7.40 \pm 1.04 v s 6.13 \pm 0.65)(p<0.001)$. Our results reinforce the concept that glycemic control plays an important role in the presence of CAD, at least in this group of type $2 \mathrm{DM}$ patients with high cardiovascular risk [23]. Even in nondiabetic individuals $\mathrm{HbA1c}$ can be associated with CAD and its severity [24].

Our lipid profile findings are similar with a study conducted by Rani S, et al. [25]. They observed that mean levels of total cholesterol in patients (DM with coronary heart disease) is $199.4 \pm 27.2 \mathrm{mg} / \mathrm{dl}$ and that of the controls (DM without coronary heart disease) is $130 \pm 28.6$ $\mathrm{mg} / \mathrm{dl}$.

The mean levels of LDL in the serum of diabetics and controls were found to be $135.56 \pm 32.57 \mathrm{mg} / \mathrm{dl}$ and
$92.5 \pm 8.3 \mathrm{mg} / \mathrm{dl}$ respectively and were statistically significant $(\mathrm{p}<0.05)$. Our observation is also similar with other studies conducted by Sahin S, et al., Sattar N, and Wilson P W [26-27].

In this study, we found a relation of NLR with the presence of coronary artery disease. There is no doubt in cardiovascular medical science that atherosclerosis is a chronic inflammatory disease [28-30]. In our study mean NLR in Group I was $2.76( \pm 0.74)$, whereas it was 1.56 $( \pm 0.15)$ in Group II. There was statistically significant association between two groups in this regards (p $<0.001$ ). Our findings are similar to a study conducted by Sahin S, et al. [9]. They also found higher mean NLR in patients with CAD group $(1.98 \pm 0.85$ vs $2.69 \pm 1.74)$ (p $<0.001$ ). Sonmez 0, et al. (2013) also found higher mean NLR in patients with coronary artery disease (2.3 vs 1.6$)$ $(\mathrm{p}<0.001)$.

Blood NLR is a new indicator of the overall inflammatory status of the body. It is a simple, inexpensive and useful marker of subclinical inflammation. Increased NLR is associated with major adverse cardiac events in diabetic patients $[11,12]$.

NLR can be a useful tool to detect and measure the future prognosis of CAD. In this study, we found a relationship between NLR and CAD proven with angiography and NLR is a useful indicator of presence of CAD.

\section{Limitation}

This study was a non-randomized single center study that included a relatively small number of patients was subject to selective bias. We did not compare the prognostic value of NLR with other inflammatory markers such as: CRP, interleukin-1 (IL-1), interleukin-6 (IL-6) and TNF- $\alpha$ etc. We also did not exclude the stressful condition and autoimmune disease because of financial resource and short hospital stay of patients.

\section{Conclusion}

Increased Neutrophil lymphocyte ratio (NLR) is a risk factor for developing coronary thrombosis leading to coronary artery disease (CAD). By the assessment of NLR we can take preventive measure and precaution to reduce the risk of coronary artery disease in type 2 diabetic patients. NLR is a simple, cost effective, readily available test and could be calculated easily to predict the risk of $\mathrm{CAD}$ and can take extra measure and preventive 
intervention to prevent CAD. It can also uses as a simple tool for an independent indicator, prognosis and follow up of CAD in type 2 diabetes mellitus patients.

\section{Acknowledgement}

Authors of this study are thankful to the authority of the Department of Cardiology, BSMMU and the Department of Clinical Pathology, BSMMU, for their nice cooperation during sample collection, laboratory procedure and also thankful to the study subjects for their active and enthusiastic participation.

\section{References}

1. American Diabetic Association (2013) Standards of medical care in diabetes Diabetic care 36(1): 11-66.

2. Akhter A, Fatema K, Afroz A, Bhowmik B, Ali L, et al. (2011) Prevalence of Diabetes Mellitus and its Associated Risk Indicators in a Rural Bangladeshi Population. The Open Diabetes Journal 411(1): 6-13.

3. Morrish NJ, Wang SL, Stevens LK, Fuller JH, Keen H (2001) Mortality and Causes of Death in the Who Multinational Study of Vascular Disease in Diabetes. Diabetologia 44(2): 14-21.

4. Folsom AR, Aleksic N, Catellier D, Juneja HE, Wu KK (2002) C Reactive Protein and Incident Coronary Heart Disease in the Atherosclerosis Risk in Communities (Aric) Study. American Heart J 144(2): 233-238.

5. Huxley R, Barzi F, Woodward M (2006) Excess risk of fatal coronary heart disease associated with diabetes in men and women: meta-analysis of 37 prospective cohort studies. BMJ 332: 73-78.

6. Ateş AH, Canpolat U, Yorgun H, Kaya EB, Sunman H (2011) Total white blood cell count is associated with the presence, severity and extent of coronary atherosclerosis detected by dual source multislice computed tomographic coronary angiography. Cardiol J 18(4): 371-377.

7. Horne BD, Anderson JL, John JM, Weaver A, Bair TL (2005) Intermountain Heart Collaborative Study Group et al. which white blood cell subtypes predict increased cardiovascular risk? J Am Coll Cardiol 45(10): 1638-1643.
8. Madjid M, Awan I, Willerson JT, Casscells SW (2004) Leukocyte count and coronary heart disease implications for risk assessment. J Am Coll Cardiol 44(10): 1945-1956.

9. Sahin S, Sarikaya S, Akyol L, Altunkas F, Karaman K (2013) Evaluation of neutrophil to lymphocyte ratio as an indicator of presence of coronary artery disease in diabetic patients. National journal of medical research 3(4): 300-303.

10. Sönmez O, Ertaş g, Bacaksız A, Tasal A, Erdoğan E (2013) Relation of neutrophil -to- lymphocyte ratio with the presence and complexity of coronary artery disease: an observational study. Anadolu Kardiyol Derg 13: 662-667.

11. Azab B, Chainani V, Shah, Mcginn JT (2013) Neutrophil lymphocyte ratio as a predictor of major adverse cardiac events among diabetic population A 4 year follows up study. Angiology 64(6): 456-465.

12. Lee GK, Lee LC, Chong E, Lee CH, Teo SG, et al. (2012) The Long-Term Predictive Value of the Neutrophil-to Lymphocyte Ratio in Type 2 Diabetic Patients Presenting with Acute Myocardial Infarction. QJM 105(11): 1075-1082.

13. Zahorec R (2001) Ratio of Neutrophil to Lymphocyte Counts Rapidand Simple Parameter of Systemic Inflammation and Stress in Critically ill. Bratisl Lek Listy 102(1): 5-14.

14. Shen XH, Chen Q, Shi Y, Li HW (2010) Association of Neutrophil/Lymphocyte Ratio with Long-Term Mortality after St Elevation Myocardial Infarction Treated with Primary Percutaneous Coronary Intervention. Chin Med J 123(23): 3438-3443.

15. Assiri AS, Jamil AM, Mahfouz AA, Mahmoud ZS, Ghallab M (2012) Diagnostic importance of platelet parameters in patients with acute coronary syndrome admitted to a tertiary care hospital in southwest region, Saudi Arabia. J Saudi Heart Association 24(1): 17-21.

16. Al-Saif SM, Al Habib KF, Ullah A, Hersi A, Al Faleh H (2012) Age and its relationship to acute coronary syndromes in the Saudi Project for Assessment of Coronary Events (SPACE) registry: The SPACE age study. J Saudi Heart Association 24(1): 9-16.

17. Siddique MA, Prakash Shrestha M, Salman M, Haque KMHSS, Ahmed MK, et al. (2010) Age-Related 
Differences of Risk Profile and Angiographic Findings in Patients with Coronary Heart Disease. BSMMU J 3(1): 13-17.

18. Ullah M, Sayami LA, Khan MR, Jahan A, Rahman Z, et al. (2011) In Hospital Outcome of Myocardial Infarcton in nondiabetic patients with high on admission blood glucose level. Cardiovasc J 3(2): 143148.

19. Bittencourt C, Piveta VM, Oliveira CSV, Felipe Crispim, Deyse Meira, et al. (2014) Association of classical risk factors and coronary artery disease in type 2 diabetic patients submitted to coronary angiography. Am J Cardiol 96: 343-346.

20. Joshi P, Islam S, Pais P, Reddy S, Dorairaj P, et al. (2007) Risk Factors for Early Myocardial Infarction in South Asians Compared With Individuals in Other Countries. JAMA 297(3): 286-294.

21. Paudel R, Panta OB, Paudel B, Paudel K, Pathak OK, et al. (2009) Acute Coronary Syndrome In Elderly The Difference Compared With Young In Intensive Care Unit Of A Tertiary Hospital In Western Nepal. Journal of Clinical and Diagnostic Research 3(1): 1289-1296.

22. Sayeed MA, Mahtab H, Sayeed S, Begum T, Khanam PA, et al. (2010) Prevalence and risk factors of coronary heart disease in a rural population of bangladesh. Ibrahim Med Coll J 4(2): 37-43.
23. Pistrosch F, Natali A, Hanefeld M (2011) is hyperglycemia a cardiovascular risk factor? Diabetes Care 34 (2): S128-131.

24. Ashraf H, Boroumand MA, Amirzadegan A, Talesh SA, Davoodi G (2013) Hemoglobin A1C in non diabetic patients: an independent predictor of coronary artery disease and its severity. Diabetes Research Clinical Practice 102(3): 225-232.

25. Surekha Rani H, Madhavi G, Ramachandra R, Sahay BK, Jyothy A (2005) risk factors for coronary heart disease in type ii diabetes mellitus. Indian Journal of Clinical Biochemistry 20(2): 75-80.

26. Sattar N (2013) Revisiting the links between glycaemia, diabetes and cardiovascular disease. Diabetologia 56(4): 686-695.

27. Wilson PW, D Agostino RB, Levy D, Belanger AM, Silbershatz H, et al. (1988) Prediction of coronary heart disease using risk factor categories. 97(18): 1837-1847.

28. Ross R (1999) Atherosclerosis an Inflammatory Disease. N Engl J Med 340(2): 115-126.

29. Libby P, Ridker PM, Maseri A (2002) Inflammation and atherosclerosis. Circulation 105(9): 1135-1143.

30. Herrick JB (1912) Clinical features of sudden obstruction of the coronary arteries. JAMA 59: 20152022. 